NOTA CIENTÍFICA

\title{
AVALIAÇÃO DA RESPOSTA DE TRÊS CULTIVARES DE OLIVEIRA AO CULTIVO IN VITRO SOB DIFERENTES COMPRIMENTOS DE ONDA LUMINOSA E EFEITOS DA COMBINAÇÃO DE ZEATINA E ÁCIDO GIBERÉLICO
}

\author{
RESPONSE EVALUATION OF THREE OLIVE CULTIVARS TO THE IN VITRO \\ CULTIVATION UNDER DIFFERENT LIGHT WAVELENGTH AND THE EFFECTS \\ OF THE COMBINATION BETWEEN ZEATIN AND GIBBERELLIC ACID
}

\author{
Lorena Pastorini DONINI ${ }^{1}$ \\ Márcia Wulff SCHUCH ${ }^{2}$ \\ Mirian de Farias RIBEIRO ${ }^{3}$ \\ Joseane Almeida de SOUZA 4 \\ Gustavo Campos SOARES ${ }^{3}$
}

\begin{abstract}
RESUMO
A propagação da oliveira normalmente é realizada através de estacas lenhosas, mas a viabilidade da estaquia está condicionada a inúmeros fatores. Diante disso, a cultura de tecidos pode ser uma alternativa para a propagação desta espécie. Foram realizados dois experimentos com o objetivo do estabelecimento in vitro de três cultivares de oliveira sob diferentes tipos de luz e de avaliar a combinação de zeatina e ácido giberélico no estabelecimento in vitro de oliveira cv. Koroneiki. No primeiro experimento foram utilizados segmentos nodais de três cultivares de oliveira (Picual, Frantoio e Koroneiki) e diferentes qualidades de luz (branca, vermelha, azul e verde) que foram cultivados em meio MS $+8,8$ umol L-1 BAP $+4,33$ umol L-1 $\mathrm{AG}_{3}+0,49$ umol L-1 AIB. A cultivar Frantoio foi a que apresentou maior taxa de oxidação, aos 21 e 28 dias de cultivo; a luz branca promoveu maior percentagem de sobrevivência, e dentre as cultivares, a Koroneiki foi superior às demais; para estabelecimento observou-se que a luz branca foi superior às demais para Koroneiki e não diferiu da verde para Picual; não foi observada contaminação bacteriana e a contaminação fúngica não apresentou diferenças estatísticas. No segundo experimento segmentos nodais da cultivar Koroneiki foram cultivados em meios de cultura com diferentes concentrações de zeatina (10 e 20 umol L-1) combinadas ou não com 10 umol L-1 de $\mathrm{AG}_{3}$. A adição de zeatina e ácido giberélico ao meio de cultura não foi eficaz para o estabelecimento de oliveira cv. Koroneiki; como nã̃o houve diferença entre concentrações de zeatina, a utilização de 10 umol $\mathrm{L}^{-1}$ já é suficiente e proporciona redução dos custos laboratoriais.
\end{abstract}

Palavras-chave: Oleaceae; Olea europaeae; micropropagação.

\begin{abstract}
Usually olive propagation is done by hardwood cuttings; however cutting viability is dependent of innumerous factors. Therefore, tissue culture may be a good alternative to propagate this specie. Two experiments were carried out aiming to establish in vitro three olives cultivars under different light conditions and evaluate the zeatin and gibberellic acid combination on in vitro establishment of the olive tree cultivar Koroneiki. In the first experiment it was used nodal segments of three olives cultivars (Picual, Frantoio and Koroneiki) and different light quality (fluorescent, red, blue and green). They were cultivated into medium MS $+8.8 \mathrm{umol} \mathrm{L}^{-1} \mathrm{BAP}+4.33 \mathrm{umol} \mathrm{L}^{-1} \mathrm{GA}_{3}+0.49 \mathrm{umol} \mathrm{L}^{-1}$ IBA. 'Frantoio' showed the highest oxidation rates at the $21^{\text {st }}$ and $28^{\text {th }}$ days of cultivation. The fluorescent light provided the highest survival percentage and among cultivars 'Koroneiki was superior to others. Regarding to establishment it was observed that the fluorescent light was greater for 'Koroneiki' and did not differ from green for 'Picual'. It was not observed bacterial contamination and the fungal contamination did not present statistics differences. At the second experiment nodal segments of 'Koroneiki' were cultivated in culture

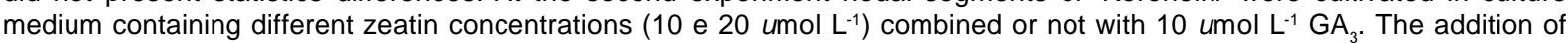
zeatin and gibberellic acid into the culture medium was not efficient for the in vitro establishment of olive cultivar Koroneiki. As there was not difference between zeatin concentrations the use of $10 \mathrm{umol} \mathrm{\textrm {L } ^ { - 1 }}$ is sufficient and provides reductions of laboratorial costs.
\end{abstract}

Key-words: Oleaceae; Olea europaeae; micropropagation.

\footnotetext{
${ }^{1}$ Doutoranda em Agronomia (Fruticultura de Clima Temperado), Laboratório de Micropropagação de Plantas Frutíferas, Departamento de Fitotecnia, FAEM, UFPel. Iorenadonini@yahoo.com.br

${ }^{2}$ Engenheira Agrônoma, Dra., Professora do Departamento de Fitotecnia, FAEM/UFPel. Laboratório de Micropropagação de Plantas Frutíferas, Departamento de Fitotecnia, FAEM, UFPel.

${ }^{3}$ Laboratório de Micropropagação de Plantas Frutíferas, Departamento de Fitotecnia, FAEM, UFPel. Bolsista PIBIC/CNPq

${ }^{4}$ Doutoranda em Agronomia (Fruticultura de Clima Temperado), Laboratório de Micropropagação de Plantas Frutíferas, Departamento de Fitotecnia, FAEM, UFPel
} 


\section{INTRODUÇÃO}

O cultivo de oliveira (Olea europaea L.) adquiriu especial relevância em todo o mundo, pelo fato de o azeite de oliva ser benéfico à saúde humana, pela sua comprovada eficácia na proteção de enfermidades cardiovasculares e por ser muito utilizado como veículo na confecção de produtos farmacêuticos (AWAN et al., 2003; PIO et al., 2005).

A oliveira é propagada vegetativamente por enxertia e estaquia, entretanto, quando se utilizam propágulos de grande tamanho, são observadas desvantagens. A propagação por sementes não é aconselhável em função da variabilidade genética e longo período juvenil, além da baixa germinação em condições de campo, inviabilizando a propagação comercial (DUTRA et al., 2004; OLIVEIRA et al., 2006).

De acordo com PIO et al. (2005), o Brasil é um dos maiores importadores de produtos de oliveira da América do Sul, sendo a Argentina um dos maiores fornecedores, além da Espanha e Portugal. Estes autores ressaltam que, até os dias de hoje, a olivicultura no Brasil não se tornou uma alternativa rentável e viável para os produtores, devido principalmente a manejos inadequados e falta de conhecimento de modernas técnicas de formação e condução dos pomares. Em vista disso, a cultura de tecidos pode ser uma prática viável para a propagação da oliveira.

A utilização de técnicas de cultura de tecidos com o objetivo de melhorar a rentabilidade das culturas, tem-se apresentado como um instrumento importante e pode ser explorado pelos pesquisadores (OLIVEIRA et al., 2006). Um aspecto fundamental para realizar a micropropagação de uma planta frutífera é o domínio da tecnologia de propagação em laboratório, o qual é o resultado de estudos realizados com os fatores que afetam o crescimento e o desenvolvimento das plantas in vitro.

Durante o estabelecimento in vitro, a adição de fitorreguladores tem o objetivo principal de suprir as possíveis deficiências dos teores endógenos de hormônios nos explantes que se encontram isolados das regiões produtoras na planta-matriz. Simultaneamente, a adição de fitorreguladores estimula certas respostas tais como alongamento ou multiplicação da parte aérea (GRATTAPAGLIA e MACHADO, 1998). De acordo com KHAN et al. (2002) os reguladores de crescimento e a composição do meio de cultura são fatores essenciais para a proliferação e regeneração de oliveira in vitro. Além disso, a luz é um fator fundamental para o desenvolvimento das plantas, seja por ação direta ou indireta na regulação do seu metabolismo. No entanto, as plantas não dependem apenas da presença ou ausência de luz, mas também da variação da qualidade luminosa (ERIG e SCHUCH, 2005).

Este trabalho teve como objetivos o estabelecimento in vitro de diferentes cultivares de oliveira sob diferentes tipos de luz e avaliação de diferentes combinações de zeatina e ácido giberélico no estabelecimento in vitro de oliveira cv. Koroneiki.

\section{MATERIAL E MÉTODOS}

O presente trabalho foi dividido em dois experimentos realizados no Laboratório de Micropropagação de Plantas Frutíferas, Departamento de Fitotecnia da Faculdade de Agronomia Eliseu Maciel, da Universidade Federal de Pelotas, RS.

As plantas matrizes de oliveira, mantidas em casa de vegetação, foram pulverizadas com o antibiótico Agrimicina (Estreptomicina) e o fungicida Cercobin (Thiophanate-methyl) nas doses de 2,4 e $0,7 \mathrm{~g} \mathrm{~L}^{-1}$ do produto comercial, respectivamente, visando diminuir a contaminação in vitro.

Como explantes foram utilizados segmentos nodais com aproximadamente $1 \mathrm{~cm}$ de comprimento, obtidos de brotações novas de plantas de oliveira das cultivares Picual, Frantoio e Koroneiki.

Em laboratório foram retiradas as folhas dos segmentos nodais, na altura do pecíolo e, o material foi desinfestado com imersão em álcool $70 \%$ por 30 segundos, seguido de imersão em solução de hipoclorito de sódio (2,5\% do princípio ativo), adicionado de uma gota de Tween 20 , durante 15 min. Após este período, o material foi lavado por 3 vezes em água destilada e submetido a dois experimentos.

Experimento 1: Estabelecimento in vitro de cultivares de oliveira sob diferentes qualidades de luz

Para o estabelecimento in vitro dos segmentos nodais o meio de cultura utilizado foi composto pelos sais e vitaminas de MURASHIGE e SKOOG (1962) (MS) adicionado de 8,8 umol L-1 BAP $+4,33$ umol L-1 GA $_{3}+0,49$ umol L-1 IBA (ZACCHINI e AGAZIO, 2004). $O \mathrm{pH}$ foi ajustado para 5,8 antes da inclusão do ágar $(0,8 \%)$ e autoclavado a $121{ }^{\circ} \mathrm{C}$ e $1,5 \mathrm{MPa}$ por $20 \mathrm{~min}$. Foram utilizados tubos de ensaio $(20 \times 150 \mathrm{~mm})$ com $8 \mathrm{~mL}$ de meio de cultura. Após a inoculação, os explantes foram mantidos em sala de crescimento a $25 \pm 2{ }^{\circ} \mathrm{C}$, no escuro, por uma semana. Depois disso, o material foi transferido para fontes de luz com diferentes comprimentos de onda: azul, verde e vermelha com a utilização de filtros coloridos de acetato de celulose, do tipo Lee Filters (Walworth Ind. Estate, Andover, England), a luz branca foi obtida através do uso de lâmpadas fluorescentes. Todo o material foi mantido sob fotoperíodo de $16 \mathrm{~h}$ e densidade de fluxo de fótons de 27 umol m $\mathrm{m}^{-2} \mathrm{~s}^{-1}$.

$\mathrm{O}$ experimento constou de um fatorial $\mathrm{A} \times \mathrm{B}$ ( $A=$ cultivares, $B=$ fontes de luz). As fontes de variação dos tratamentos foram cultivares: Picual, Frantoio e Koroneiki e fontes de luz: branca, azul, verde e vermelha, totalizando 12 tratamentos. O delineamento experimental utilizado foi inteiramente casualizado com quatro repetições por tratamento, Cada parcela experimental foi constituída por cinco tubos, contendo um explante cada.

Foram realizadas avaliações aos 14, 21 e 28 dias quanto à percentagem de contaminação 
bacteriana, percentagem de contaminação fúngica e percentagem de explantes oxidados. Aos 45 dias de cultivo o material foi avaliado quanto à percentagem de sobrevivência, indicada pela coloração verde do segmento nodal, e quanto à percentagem de estabelecimento, que foi determinado pelo desenvolvimento de primórdios foliares (presença de folhas ou brotações).

Experimento 2: Estabelecimento in vitro da cultivar Koroneiki em meio de cultura WPM com combinações de zeatina e ácido giberélico $\left(\mathrm{AG}_{3}\right)$

$O$ meio de cultura utilizado para 0 estabelecimento dos segmentos nodais in vitro foi constituído pelos sais e vitaminas de WPM (LLOYD e MCCOWN, 1980) adicionado de duas concentrações de zeatina (10 e 20 umol $\left.\mathrm{L}^{-1}\right)$ combinadas ou não com $10 u_{\mathrm{mol} \mathrm{L}}^{-1}$ de ácido giberélico. $\mathrm{O} p H$ foi ajustado para 5,8 antes da inclusão do ágar $(0,8 \%)$ e autoclavado a $121 \stackrel{\circ}{\circ}$ e $1,5 \mathrm{MPa}$ por $20 \mathrm{~min}$. Foram utilizados tubos de ensaio $(20 \times 150 \mathrm{~mm})$ com $8 \mathrm{~mL}$ de meio de cultura. Após a inoculação, os explantes foram mantidos em sala de crescimento a $25 \pm 2{ }^{\circ} \mathrm{C}$, no escuro por um período de sete dias, visando a diminuição de oxidação. Depois disso o material foi transferido para luz, fotoperíodo de $16 \mathrm{~h}$ e densidade de fluxo de fótons de 27 umol m $\mathrm{m}^{-2} \mathrm{~s}^{-1}$.

$O$ experimento constou de um fatorial $A \times B$ $\left(A=\right.$ concetrações de zeatina, $B=$ com ou sem $\left.A G_{3}\right)$. Os tratamentos constituiram-se de duas concentrações de zeatina (10 e $\left.20 \mathrm{umol} \mathrm{L}^{-1}\right)$ e ácido giberélico (com e sem), totalizando 4 tratamentos. O delineamento experimental utilizado foi inteiramente casualizado com quatro repetições por tratamento, onde cada repetição constituiu-se de cinco tubos, com um explante cada.

Foram realizadas avaliações aos 7,14 e 21 dias quanto à percentagem de contaminação bacteriana, percentagem de contaminação fúngica e percentagem de explantes oxidados. Aos 45 dias de cultivo o material foi avaliado quanto à percentagem de sobrevivência, indicada pela coloração verde do segmento nodal, e quanto à percentagem de estabelecimento, que foi determinado pelo desenvolvimento de primórdios foliares (presença de folhas ou brotações).

Para os dois experimentos os dados foram submetidos à análise de variância e as médias dos tratamentos comparadas estatisticamente pelo teste de Duncan com probabilidade de $5 \%(p<0,05)$, através do uso do programa estatístico SANEST (ZONTA e MACHADO, 1987).

\section{RESULTADOS E DISCUSSÃO}

\section{Experimento 1: Estabelecimento in vitro de cultivares de oliveira sob diferentes qualidades de luz}

Através da análise da variância verificou-se que houve diferenças significativas entre cultivares para a variável percentagem de oxidação, para percentagem de sobrevivência houve diferenças significativas para luzes e para cultivares, e para a variável percentagem de estabelecimento houve diferenças significativas para a interação entre os fatores luzes e cultivares.

A cultivar Frantoio foi a que apresentou maior taxa de oxidação, aos 21 e 28 dias de cultivo em relação às demais cultivares utilizadas (Tabela 1 ). No estabelecimento de diferentes cultivares de Prunus sp., RODRIGUES et al. (2003) verificaram que uma de nove cultivares testadas, a cultivar Santa Rosa, apresentou maior percentual de oxidação que as demais. Estes autores atribuem isso ao fato de esta cultivar apresentar altas concentrações de compostos fenólicos totais, e os diferentes tipos de fenóis presentes nos tecidos, ao entrarem em contato com o oxigênio, sofrem reações de oxidação, cujos produtos resultantes são tóxicos, causando escurecimento e necrose do tecido vegetal.

Para a variável percentagem de sobrevivência, a luz branca promoveu maiores médias (84,99\%), sendo superior aos demais tipos de luz utilizados, e, dentre as cultivares, Koroneiki foi superior às demais, apresentando maiores médias $(88,00 \%)$ (Tabela 2$)$.

TABELA 1 - Média de explantes oxidados aos 14, 21 e 28 dias de cultivo in vitro de diferentes cultivares de oliveira (Picual, Frantoio e Koroneiki) independente da qualidade de luz utilizada. UFPel, PelotasRS. 2006.

\begin{tabular}{lccc}
\hline \multicolumn{1}{c}{ Cultivares } & \multicolumn{1}{c}{ Dias } \\
\cline { 2 - 4 } & 14 & 21 & 28 \\
\hline Frantoio & $2,49 \mathrm{a}$ & $11,36 \mathrm{a}$ & $30,06 \mathrm{a}$ \\
Koroneiki & $1,01 \mathrm{a}$ & $1,01 \mathrm{~b}$ & $4,83 \mathrm{~b}$ \\
Picual & $0,33 \mathrm{a}$ & $1,33 \mathrm{~b}$ & $2,49 \mathrm{~b}$
\end{tabular}

Médias seguidas de mesma letra minúsculas nas colunas não diferem entre si pelo teste de Duncan ao nível de $5 \%$ de probabilidade. 
DONINI, L.P. et al. Avaliação da resposta de três cultivares...

TABELA 2 - Média de explantes sobreviventes aos 45 dias de cultivo de diferentes cultivares de oliveira (Picual, Frantoio e Koroneiki) sob diferentes qualidades de luz (branca, azul, verde e vermelha). UFPel, Pelotas-RS. 2006.

\begin{tabular}{|c|c|}
\hline Cultivares & Médias \\
\hline Koroneiki & $88,00 \mathrm{a}$ \\
\hline Picual & $36,33 \mathrm{~b}$ \\
\hline Frantoio & $32,39 \mathrm{~b}$ \\
\hline Luzes & Médias \\
\hline Branca & $84,99 \mathrm{a}$ \\
\hline Verde & $51,84 \mathrm{~b}$ \\
\hline Vermelha & $48,32 \mathrm{~b}$ \\
\hline Azul & 27,07 b \\
\hline
\end{tabular}

Médias seguidas de mesma letra minúsculas nas colunas não diferem entre si pelo teste de Duncan ao nível de $5 \%$ de probabilidade.

A luz branca promoveu maior taxa de estabelecimento e que assim como para sobrevivência, a cultivar Koroneiki também apresentou maiores taxas de estabelecimento $(81,23 \%)$, mas não diferiu da Picual $(65,34 \%)$ quando a luz branca foi utilizada. O mesmo aconteceu com a luz azul, embora tenha apresentado menores médias em comparação com a luz branca, essas duas cultivares se mostraram melhores que a Frantoio. Quando a luz verde foi utilizada a cultivar
Picual mostrou-se a melhor $(34,65 \%)$ das três utilizadas (Tabela 3).

Foi observada uma baixa taxa de contaminação neste experimento, para contaminação fúngica a média foi de $1,66 \%$, não apresentando diferenças entre os tratamentos, e para contaminação bacteriana foi nula. A baixa taxa de contaminação se deve a eficácia do processo de desinfestação utilizado para essas cultivares.

TABELA 3 - Média de explantes estabelecidos aos 45 dias de cultivo in vitro de diferentes cultivares (Picual, Frantoio e Koroneiki) sob diferentes qualidades de luz (branca, azul, verde e vermelha). UFPel, Pelotas-RS. 2006.

\begin{tabular}{lcccc}
\hline \multirow{2}{*}{ Cultivares } & \multicolumn{3}{c}{ Luzes } \\
\cline { 2 - 5 } & Branca & Vermelha & Azul & Verde \\
\hline Koroneiki & $81,23 \mathrm{a} \mathrm{A}$ & $1,33 \mathrm{a} \mathrm{B}$ & $19,57 \mathrm{a} \mathrm{B}$ & $1,33 \mathrm{~b} \mathrm{~B}$ \\
Picual & $65,34 \mathrm{a} \mathrm{A}$ & $1,33 \mathrm{a} \mathrm{C}$ & $8,01 \mathrm{ab} \mathrm{BC}$ & $34,65 \mathrm{a} \mathrm{AB}$ \\
Frantoio & $15,11 \mathrm{~b} \mathrm{~A}$ & $5,27 \mathrm{a} \mathrm{A}$ & $0,00 \mathrm{~b} \mathrm{~A}$ & $1,33 \mathrm{~b} \mathrm{~A}$
\end{tabular}

Médias seguidas de mesma letra minúsculas nas colunas, e maiúsculas nas linhas, não diferem entre si pelo teste de Duncan ao nível de $5 \%$ de probabilidade.

\section{Experimento 2: Estabelecimento in vitro da cultivar Koroneiki em meio de cultura WPM com combinações de zeatina e ácido giberélico $\left(\mathrm{AG}_{3}\right)$}

Os valores médios de percentagem de contaminação fúngica e de estabelecimento não apresentaram diferenças significativas entre os tratamentos. Para sobrevivência observaram-se diferenças significativas para o fator $\left(\mathrm{AG}_{3}\right)$ (Tabela 4) Não foram observadas contaminação bacteriana e oxidação durante as avaliações.

No presente trabalho, a média de contaminação observada foi de $26,3 \%$, aos 28 dias de cultivo. No estabelecimento in vitro de meristemas de Pyrus spp., ERIG e FORTES (2002) observaram taxa de contaminação (fúngica + bacteriana) de $18,8 \%$. Para cultivares de macieira,
ERIG e SCHUCH (2003) obtiveram taxa quase nula de contaminação fúngica $(1,4 \%)$.

A média de explantes estabelecidos de oliveira cultivar Koroneiki foi de 51,05\%, ROCHA et al. (2005) observaram médias de $99,6 \%$ de estabelecimento in vitro de segmentos nodais de Prunus Mr.S. 2/5, e assim, como no presente trabalho, não observaram explantes oxidados.

Para sobrevivência observou-se diferenças para presença e ausência de $\mathrm{AG}_{3}$, onde houve maior percentagem de sobrevivência quando utilizados os meios sem adição de $A_{3}$. Pode-se observar também que os explantes estabelecidos em meio com combinação de zeatina e $\mathrm{AG}_{3}$ apresentaram formação de calos nas extremidades cortadas, já quando $A_{3}$ não foi adicionado a percentagem foi estatisticamente inferior (Tabela 4). 
DONINI, L.P. et al. Avaliação da resposta de três cultivares...

TABELA 4 - Média de sobrevivência, e formação de calos de explantes de oliveira cv. Koroneiki cultivadas in vitro em meio de cultura WPM com combinações de zeatina e $A_{3}$.

\begin{tabular}{|c|c|c|}
\hline \multirow{2}{*}{$\mathrm{AG}_{3}$} & \multicolumn{2}{|c|}{ Variáveis } \\
\hline & Sobrevivência (\%) & Formação de calos (\%) \\
\hline Sem & $82,57 \mathrm{a}$ & $11,11 \mathrm{~b}$ \\
\hline Com & $53,50 \mathrm{~b}$ & $50,00 \mathrm{a}$ \\
\hline
\end{tabular}

Médias seguidas de mesma letra minúsculas nas colunas não diferem entre si pelo teste de Duncan ao nível de $5 \%$ de probabilidade.

Ao contrário do presente trabalho, onde observou-se formação de calos quando adicionado $\mathrm{AG}_{3}$ ao meio de cultura em combinação com zeatina, KHAN et al. (2002) no cultivo in vitro de oliveira cv. Leccino não observaram calos quando utilizaram concentrações de 0 a $8 u \mathrm{M}$ de $\mathrm{AG}_{3}$, somente quando utilizaram KIN e BAP, estes autores atribuem formação de calos ao acúmulo de citocininas nos brotos.

\section{CONCLUSÕES}

1) Há maior sobrevivência da cultivar Koroneiki quando cultivada sob luz branca.

2) As cultivares Koroneiki e Picual apresentam maior taxa de estabelecimento in vitro quando cultivadas sob luz branca.

3) A combinação de zeatina e $\mathrm{AG}_{3}$ não é eficaz para o estabelecimento in vitro de oliveira cv. Koroneiki quando em luz vermeha, azul e verde

4) A utilização de 10 umol $\mathrm{L}^{-1}$ de zeatina proporciona redução dos custos laboratoriais.

\section{REFERÊNCIAS}

1. AWAN, A.A.; IGBAL, A.; JAYED, M.; IDRIS, G. Response of olive hard wood cuttings to different growth media and basal injuries for propagation. Asian Journal of Plant Sciences, v. 2, n. 12, p. 883-886, 2003.

2. DUTRA, L.F.; OLIVEIRA, A.F.; FRÁGUAS, C.B.; PASQUAL, M. Multiplicação in vitro de oliveira (Olea europaea L.). Ciência e Agrotecnologia, v. 28, n. 1, p. 220-223, 2004.

3. ERIG, A.C.; FORTES, G.R.L. Estabelecimento de pereira (Pyrus spp.) in vitro a partir de meristemas e gemas. Ciência Rural, v. 32, n. 4, p. 577-582, 2002.

4. ERIG, A.C.; SCHUCH, M.W. Tipo de explante e controle da contaminação e oxidação no estabelecimento in vitro de plantas de macieira (Malus domestica BORKH.) cvs. Galaxy, Maxigala e Mastergala. Revista Brasileira de Agrociência, v. 9, n. 3, p. 221-227, 2003.

5. ERIG, A.C.; SCHUCH, M.W. Tipo de luz na multiplicação in vitro de framboeseira (Rubus idaeus L.) "Batum". Revista Brasileira de Fruticultura, v. 27, n. 3, p. 488-490, 2005.

6. GRATTAPAGLIA, D.; MACHADO, M.A. Micropropagação. In: TORRES, A.C.; CALDAS, L.S.; BUSO, J.A. (Eds.) Cultura de tecidos e transformação genética de plantas. Brasília: Embrapa SPI, Embrapa - CNPH, 1998. p. 183-260.

7. KHAN, M.R.; RACED, H.; CARWASH, A. Development of aseptic protocols in olive (Olea europa L.) cv. Pantaloon. Asian Journal of Plant Sciences, v. 1, n. 3, p. 220-221, 2002.

8. LLOYD, G.; MCCOWN, B. Commercially-feasible micropropagation of mountain laurel, kalmia latifolia, by use os shoottip culture. Combined Proceedings International Plant Propagators Society, v. 30, p. 421- 427, 1980.

9. MURASHIGE, T.; SKOOG, F.A revised medium for rapid growter and bioassays with tabaco tissue culture. Physiologia Plantarum, v. 15, p. 473-497, 1962.

10. OLIVEIRA, A.F.; VILLA, F.; PASQUAL, M. Aplicação de técnicas de cultura de tecidos em oliveira. Informe agropecuário, v. 27, n. 231 , p. $51-54,2006$.

11. PIO, R.; BASTOS, D.C.; BERTI, A.J.; SCARPANE FILHO, J.A.; MOURÃO FILHO, F.A.A.; ENTELMANN, F.A.; ALVES, A.S.R.; NETO, J.E.B. Enraizamento de diferentes tipos de estacas de oliveira (Olea europaea L.) utilizando ácido indolbutírico. Ciência e Agrotecnologia, v. 29, n. 3, p. 562-567, 2005.

12. ROCHA, P.S.G.; SCHUCH, M.W.; BIANCHI, V.J.; FACHINELLO, J.C.; MISTURA, C.C. Tipo de explante e estado físico do meio no estabelecimento in vitro do porta-enxerto de Prunus MR.S.2/5. Revista Científica Rural, v. 10, n. 2, p. 102-107, 2005.

13. RODRIGUES, A.C.; SILVEIRA, C.A.P.; FORTES, G.R.L.; FACHINELLO, J.C.; SILVA, J.B. Estabelecimento e multiplicação in vitro de Prunus sp. Em diferentes meios de cultivo. Revista Brasileira de Agrociência, v. 25, n. 1, p. 131-133, 2003.

14. ZACCHINI, M.; AGAZIO, M. Micorpropagation of a local olive cultivar for germoplasm preservation. Biologia Plantarum, v. 48, n. 4 , p.589-592, 2004.

15. ZONTA, E.P., MACHADO, A.A. SANEST - Sistema de análise estatística para microcomputadores. Pelotas: DMEC/IFM/UFPel, 1987. $138 \mathrm{p}$. 
